\title{
Research on the Dynamic Mechanism of Cultural Innovation in Urban Open Space
}

\author{
Kejin Liu ${ }^{1, a}$, Chunxiao $\mathrm{Xu}^{2, \mathrm{~b}}$ \\ ${ }^{1}$ No.1 East Yinghua Street, Beijing Institute of Fashion Technology, Chaoyang District, China \\ ${ }^{2}$ No.1 East Dingfuzhuang Street, Communication University of China, Chaoyang District, China \\ akejinliu_cuc@hotmail.com, ${ }^{b}$ chunxiao1993@126.com,
}

Keywords: Urban Open Space; Cultural Innovation; Space Vitality; Dynamic System; Dynamic Mechanism.

\begin{abstract}
As a new type of space, urban open space breaks through the boundaries of traditional functional zone of urban space and gradually becomes an important carrier and form of urban construction. Researches show that urban open space is becoming a new bright spot for regional economic development and social life progress in the new era, and represents an important direction of urban space innovation and function transformation. Under the impact of local culture and global culture, how to cultivate advanced culture that meets the needs of residents in the urban open space with limited scale, and how to stimulate the development of urban open space culture innovation, are the questions that the government and educational circles need to seriously consider.
\end{abstract}

\section{Introduction}

There is a close relationship between the culture development and social economic development of urban open space, which has strong theoretical and practical significance. The urban open space culture innovation is a process of blending symbiosis with economic, political, social and environmental factors, which can promote city development in an order and healthy way. Firstly, the construction of urban open space often depends on the development of cultural industries and the leisure and entertainment needs of residents. Their interaction is beneficial to the optimization and adjustment of regional industrial structure. Secondly, the cultural construction of urban open space is generally influenced by urban planning and government management, which directly reflects the political intention and political orientation to urban space. And the process of culture cultivation of urban open space is also that of the experience and feedback of residents' political life. Thirdly, the cultural innovation of urban open space has gradually become a new direction to rich urban social life and a new highland for urban culture cultivation. Urban open space integrating into social life, builds a platform and medium for interpersonal communication and social information sharing. Fourth, urban open space relies on the development of the urban physical environment, drawing on ideas from urban natural and cultural resources. It is restricted by the objective environmental form and gives the flexible adjustment to the urban natural space and living environment.

After analyzing and summarizing the related research on the open space, on spatial vitality, and on the dynamic mechanism of cultural innovation domestic and foreign education areas, this study finds that there is no enough theoretical researches on the dynamic mechanism of cultural innovation of urban open space in China, and there is also a large theoretical gap which mainly include some aspects, like that the researches on the dynamic mechanism of cultural innovation are less targeted, not revealing the general rules and lack of specific cultural innovation strategies between existing domestic researches and foreign researches.

\section{Hypothesis}

1. Illustrate the different forms of the cultural elements of urban open space;

2.Propose the dynamic subject of urban open space and explore the interaction relationship between various dynamic elements; 
3. Exploring the construction and working principle of the cultural innovation mechanism of urban open space;

4. Establish an explanatory framework for the dynamic mechanism of the cultural innovation mechanism of urban open space.

\section{Methods}

This study based on the combination of qualitative and quantitative research methods, through visiting the open space in more than 40 cities of different countries of aims at constructing the cultural innovation dynamic system of urban open space and clarifying the operational process of the dynamic mechanism of culture innovation of urban space under different leading dynamics.

According to the culture hierarchy theory, the cultural dynamic elements of urban open space are summarized into material form, behavior form, institutional form and spiritual form, and this is the theoretical start point to explore the composition and function principle of culture innovation dynamic mechanism of urban open space. The dynamic mechanism consists of the dynamic system and the mechanism of action promotion and changing, which is an empirical product after theoretical refinement based on practical behavior, and can reflect the law of operation. In this regard, the existing research findings are mainly divided into two types which are firstly proposing the dynamic body and describing the interaction relationship between various dynamic elements based on the dynamic elements of urban open space culture innovation, and secondly examining different interaction modes of social, political, market, and environmental forces from the perspective of urban sociology based on specific cases. These studies deeply recognize that the dynamic driving mechanism of urban open space culture is not the result of a single dynamic, and it requires the combined effect of multiple factors. There is a need for a more systematic research framework for dynamic mechanisms that not only reflects China's macroeconomic and social situation, but also establishes an specific explanatory framework for the operation way of cultural innovation dynamic mechanisms of urban open space. It can be seen that focusing on the cultural innovation dynamic mechanism of urban open space has theoretical innovation.

\section{Summary}

Firstly, this study illustrates the forms of cultural elements of urban open space, which mainly consist of four aspects, material form, mode form, institutional form and spiritual form. Specifically, the material form mainly includes the architectural features in the urban open space, the tangible or intangible historical culture heritage, and the natural environment system; the mode form includes the production behavior of the urban open space culture, and the consumer behavior and social interactions carried by the urban open space; The institutional form mainly includes the organization form of urban open space, the rules followed in the process of space construction and management, and the folk customs system carried by space; the spiritual form mainly includes the artistic design style embodied in the urban open space, the educational composition of learning with the help for residents to achieve self-improvement and the level of technology reflected during the process of space construction and operation.

Second, this study refers to the urban overall theory of Western sociology, and believes that the main force of cultural innovation of urban open space is mainly composed of government departments, economic organizations, social organizations and residents. According to different power subjects, it is summarized as four types of power: government regulating force, economic driving force, environmental support power, and social restraint, and extends ten types of dynamic effects. They are respectively space scale expansion power, spatial structure optimization power, expansion mode deciding power, space development motivation power, space development orientation power, spatial planning controlling power, space development tolerance power, spatial shape shaping force, spatial development driving force and space development constraint force. Establishing a dynamic source Dynamic subject - Dynamic type - Dynamic action, a four-level cultural innovation development dynamic system urban open space interpretation framework (DSSTA mode ). Through the extension 
of the culture innovation development dynamic system of urban open space, it can be inducted as the explicit and implicit dynamic effects, which constitute the perfect working principle. The explicit effect is mainly based on the amount of space, spatial distribution, spatial design, space cultural facilities, space cultural activities, number of visitors to the space and frequency of visits to the space. The implicit effects are the measure of spatial atmosphere, personal self-realization, interpersonal interaction frequency, social participation, and information flow rate. Based on the DSSTA model, the internal logic and obvious signs of cultural innovation of urban open space are clarified.

Thirdly, construct a dynamic mechanism for culture innovation of urban open space. First of all, the premise of constructing the mode is to clear-cut the formation mechanism and operation link. It mainly includes six parts: innovation subject, innovation resource, organization process, dynamic role, guarantee mechanism and constraints, covering all aspects of urban open space culture innovation. By analyzing the characteristics of the different links, a deeper understanding of the mechanism of urban open space culture innovation is formed. Then, on account of the distinction of urban open space types, this study constructs the function principle of urban open space cultural innovation dynamic mechanism, and deeply dissects the interaction relationship between various elements of urban open space cultural innovation. Then, based on the four kinds of powers, the dynamic culture mechanism of urban open space is extended to the place construction mode, behavior cultivation mode, spiritual leading mode and institution promotion mode. According to the specific differences of the cultural innovation power of urban open space, the four dynamic models are refined into nine sub-model, the creation of spatial characteristics model, environmental system upgrading model, historical heritage protection model, consumption behavior promoting model, social interaction cultivation model, and artistic aesthetic guidance. At the same time, for each operation way, the types of characteristics, the conditions of power creating, the representative cases, and the specific processes of the dynamic role are elaborated. It reveals the inner principle and external expression of the dynamic mechanism of cultural innovation in urban open space.

This research has made some explorations in both theoretical and practical terms. First of all, this study elaborates the connotation and extension of urban open space from the perspective of cultural research for the first time, and puts forward the cultural dynamic elements of urban open space based on the theory of cultural space hierarchy, and makes useful explorations in theoretical construction. Secondly, with the work of profoundly cleaning up the formal development momentum of the urban open space and distinguishing the reality, the author proposes the dynamic system of urban open space culture innovation, constructing the dynamic mechanism of urban open space culture innovation, and concluding the specific operational mechanism of the cultural innovation dynamic mechanism, having practical guiding significance for the cultural innovation of urban open space.

\section{Reference}

[1] Clark, T.N., \& Foss, G. City Ideas That Work, Special Report: Public Art Project Captures International Interest, Local Hearts[J]. Nation's Cities Weekly,1999,22(43).

[2] Sliver, Daniel and Terry, Clark. The power of scenes: quantities of amenities and qualities of places [J]. Cultural Studies,2015,09(13): 425-449.

[3] Kejin Liu. Types of Cultural Scenes in Foreign Cities and Their Creation Paths [J]. Chinese Cultural Industry Review,2019,27(01):324-338. 